\title{
Performance Analysis of the Linear Induction Motor for the Deep-Underground High-Speed GTX
}

\author{
Chan-Bae Park*, Hyung-Woo Lee** and Ju Lee ${ }^{\dagger}$
}

\begin{abstract}
In order to develop a deep-underground great train express (GTX) in South Korea, the specifications decision and development of a traction control system (including an inverter and a traction motor), which considers a variety of route conditions, must be advanced. In this study, we examined the running resistance properties of a high-speed traction system based on a variety of tunnel types and vehicle organization methods. Then, we studied the power requirements necessary for the traction motor to maintain balanced speed in the high-speed traction system. From this, we determined the design criteria for the development of a high-speed traction system for use in the deep-underground GTX. Finally, we designed a linear induction motor (LIM) for a propulsion system, and we used the finite element method (FEM) to analyze its performance as it travelled through deep-underground tunnels.
\end{abstract}

Keywords: Linear induction motor, Traction system, Electromagnetic analysis, Power consumption

\section{Introduction}

Traffic-related problems are multiplying rapidly in the densely-populated capital of the Republic of Korea. In addition, the number of long-distance commuters continues to increase as an increasing number of citizens moving to newly constructed satellite cities. In order to alleviate traffic congestion, there is a need for a comprehensive plan that shall cover the entire metropolitan area. Moreover, a fast, efficient public transportation system, which will allow passengers to travel between central Seoul and major outlying areas in less than 30 minutes, should be constructed. However, extending existing infrastructures, such as highways and railroads, can be problematic. It is extremely expensive and can decrease the aesthetic appeal of the city. For this reason, many researchers have proposed the construction of a deep-underground great train express (GTX), which is twice as fast as a conventional subway and is constructed at a depth of more than $40 \mathrm{~m}$ below ground. This system, which shall greatly contribute to the South Korean economy, is currently undergoing a government-run feasibility study [1]. The deep-underground GTX is a subterranean railway system, which makes use of the land located 40 to $50 \mathrm{~m}$ below the surface of the land. The GTX is an express train that makes a minimum number of intermediate stops. Several countries, including the United States, Russia and Ukraine,

$\dagger$ Corresponding Author: Division of Electrical and Biomedical Engineering, Hanyang University, Korea (julee@hanyang.ac.kr)

* Department of Electrical Engineering, Hanyang University (Railroad Propulsion System Research Team, Korea Railroad Research Institute), Korea (cbpark@krri.re.kr)

** Railroad Propulsion System Research Team, Korea Railroad Research Institute, Korea (krhwlee@krri.re.kr)

Received: February 22, 2011; Accepted: November 29, 2011 have incorporated deep-underground railroads into their subway systems and have been using them for many years [1]. In order to develop a deep-underground GTX in South Korea, an advanced traction control system (including an inverter and an electric motor), which considers a variety of route conditions, must be designed. Fig. 1 shows the construction concept of the deep-underground GTX at the city center.

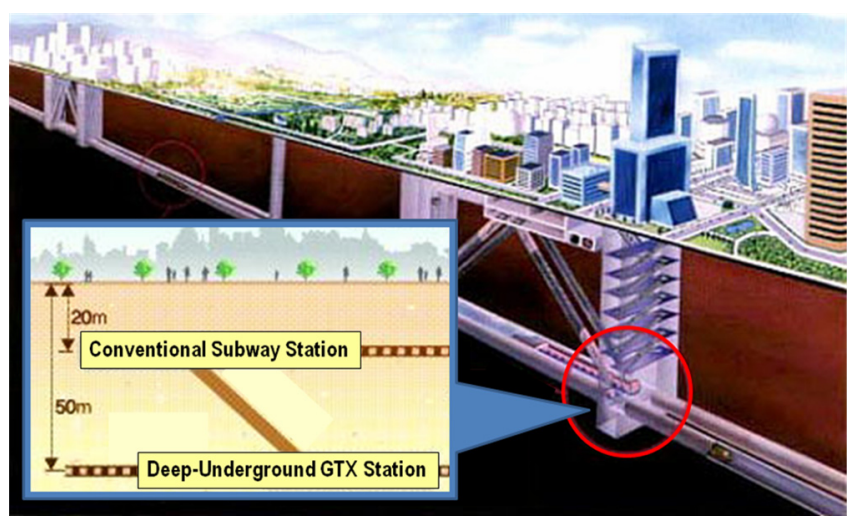

Fig. 1. Construction concept of the deep-underground GTX at the city center

In this study, we examined the running resistance properties of a high-speed traction system based on a variety of tunnel types and vehicle organization methods. Then, we studied the power requirements necessary for the traction electric motor to maintain balanced speed in the high-speed traction system. From this, we determined the design criteria for the development of a high-speed traction system for use in the deep-underground GTX. Finally, we designed a linear induction motor (LIM) for use in the 
propulsion system and employed the finite element method (FEM) to analyze its force and power consumption properties as it travels through the deep-underground tunnels.

\section{Deduction of the Design Criteria of the High- speed Traction System}

\subsection{Running resistance properties based on a variety of tunnel types and vehicle organization}

The air resistance created when a train travels through a tunnel varies depending on the tunnel's structure and type. The air resistance within the tunnel is an important factor, because it creates resistance as the train moves. When the running resistance becomes too great, trains require a large traction power source when traveling at a high speed. This increases the capacity of the traction control system. In order to create a suitable design for a train's traction control system, it is necessary to calculate the exact running resistance of the vehicle under its operation. In this study, the increasing coefficient of air resistance (IC-AR) for open ground has been set to 1 , and the increasing coefficient values of air resistance by tunnel type are shown in Table $1[2,3]$. Then, the increasing coefficient values of air resistance from Table 1 were applied to Eq. (1), and the running resistance was calculated by tunnel type. The South Korean Tilting Train eXpress (TTX) was used for evaluating the running resistance (organization: 6 vehicles, 344 tons). These are calculated as follows:

$$
\begin{gathered}
R=\left(1.3 \sqrt{\frac{10}{m}}+0.01 V\right) W+k\left(c_{0} V^{2}\right) \quad[k g f] \\
c_{0}=0.0035 S+0.0041 \frac{p L}{100}+0.002 N_{P}
\end{gathered}
$$

where $R$ is the running resistance $(\mathrm{kgf}), W$ is the total weight of the railway vehicles (tons), $m$ is the axle load (tons), $V$ is the railway vehicle speed $(\mathrm{km} / \mathrm{h}), c_{o}$ is the air resistance coefficient on open ground, $k$ is the increasing coefficient value of the air resistance, $S$ is the cross-section of a vehicle front surface $\left(\mathrm{m}^{2}\right), p$ is the circumference length of a vehicle (m), $L$ is the length of the railway vehicles $(\mathrm{m})$, and $N_{P}$ is the number of pantographs $[4,5]$.

Table 1. Increasing coefficient value of the air-resistance by tunnel type

\begin{tabular}{c|c|c}
\hline \multicolumn{2}{c|}{ Tunnel type } & IC-AR $(\mathrm{k})$ \\
\hline \multicolumn{2}{c}{ Open-ground } & 1 \\
\hline \multirow{2}{*}{$\begin{array}{c}\text { Single } \\
\text { line }\end{array}$} & By-pass tunnel interval : 250m & 1.418 \\
\cline { 2 - 3 } & By-pass tunnel interval : 500m & 1.621 \\
\cline { 2 - 3 } & Without By-pass tunnel & 3.229 \\
\hline \multicolumn{2}{c}{ Double line (Without By-pass tunnel) } & 1.612 \\
\hline
\end{tabular}

As shown in Fig. 3, the running resistance of a single-line tunnel (by-pass tunnel interval: $500 \mathrm{~m}$ ) is similar to that of a double-line tunnel (without a by-pass tunnel).

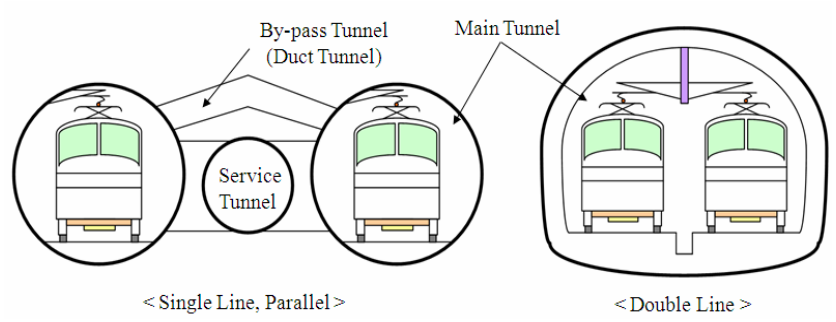

Fig. 2. Tunnel types for the deep-underground GTX

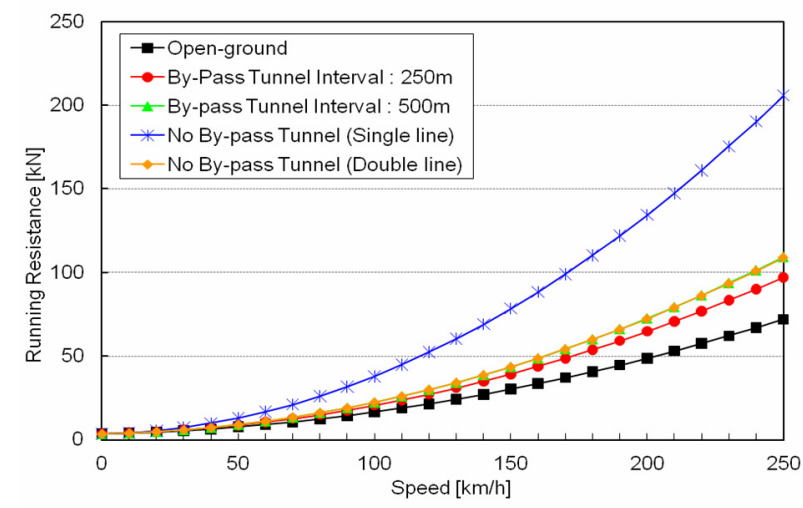

Fig. 3. Running resistance properties of the traction system based on a variety of tunnel types ( 1 organization : 6 vehicles, 344 tons).

\subsection{Traction power properties required to maintain a balanced speed}

It is important to design a traction system that can endure air resistance while maintaining balanced speed when the train travels through a tunnel. The power required for the traction motor to maintain balanced speed was calculated under various tunnel conditions. The power of the traction motor was calculated using Eq. (3) given as:

$$
P_{\text {motor }}=R_{\text {equi }}(V / 3.6) \eta \quad[W]
$$

where $P_{\text {motor }}$ is the power of the traction motor $(\mathrm{W}), R_{\text {equi }}$ is the running resistance at a balanced speed $(\mathrm{N})$, and $\eta$ is the efficiency of the power transmission (0.97). Fig. 4 shows the necessary power properties for the balanced-speed change of the traction system. As shown in Fig. 4, the design maximum speed of the traction system has been set to $170 \mathrm{~km} / \mathrm{h}$. The reason for this limitation is that the aerodynamic resistance created at speed levels above 170 $\mathrm{km} / \mathrm{h}$ result in a rapidly increasing need for power. Fig. 5 shows the necessary running distance properties for reaching the maximum speed. Assuming that GTX underground stations are spaced at intervals of 6 to $9 \mathrm{~km}$, the distance required for the train needed to reach 
maximum speed should be around 3-4.5 km [1, 6]. As shown in Fig. 5, the train can reach a speed of $170 \mathrm{~km} / \mathrm{h}$ within $4.5 \mathrm{~km}$. Meanwhile, Fig. 6 shows the necessary emergency braking distance properties of the traction system according to traveling speed. For the TTX, the emergency braking distance is less than $1,000 \mathrm{~m}$ when traveling at a speed of $160 \mathrm{~km} / \mathrm{h}$. Thus, in this study, the maximum design and operation speed levels were set at 165 and $150 \mathrm{~km} / \mathrm{h}$, respectively. Table 2 shows the design criteria of the high-speed propulsion system for use in the deep-underground GTX.

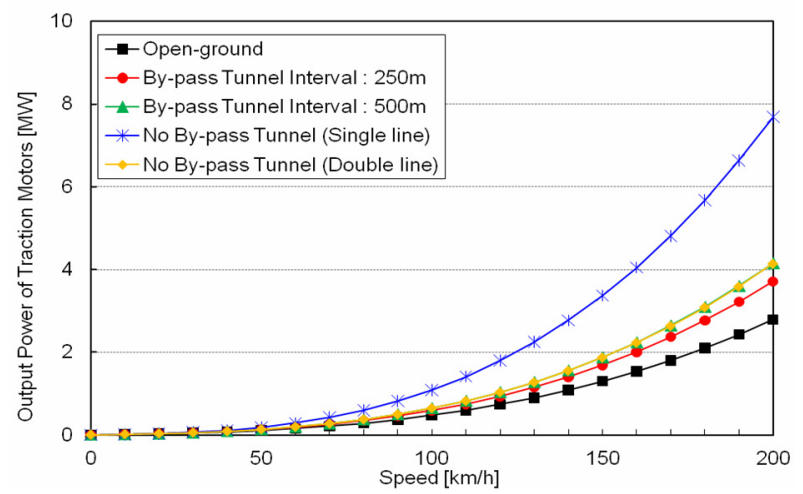

Fig. 4. Necessary power properties for the balanced-speed change of the traction system

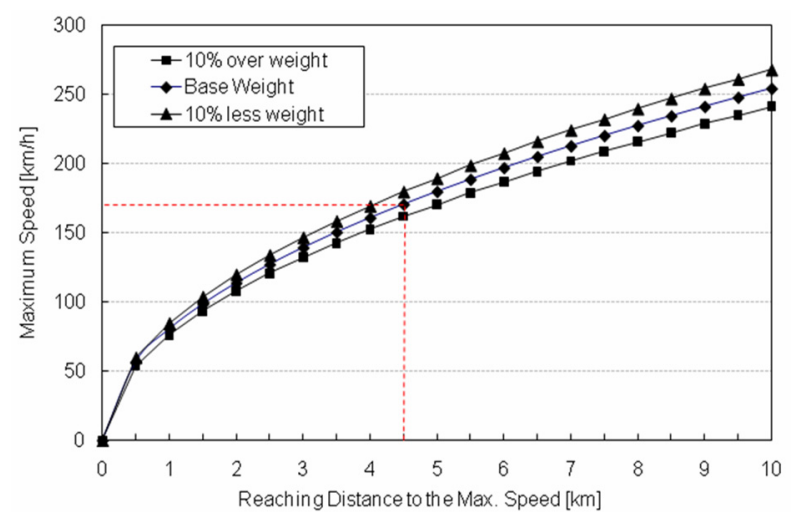

Fig. 5. Necessary running distance properties for reaching the maximum speed

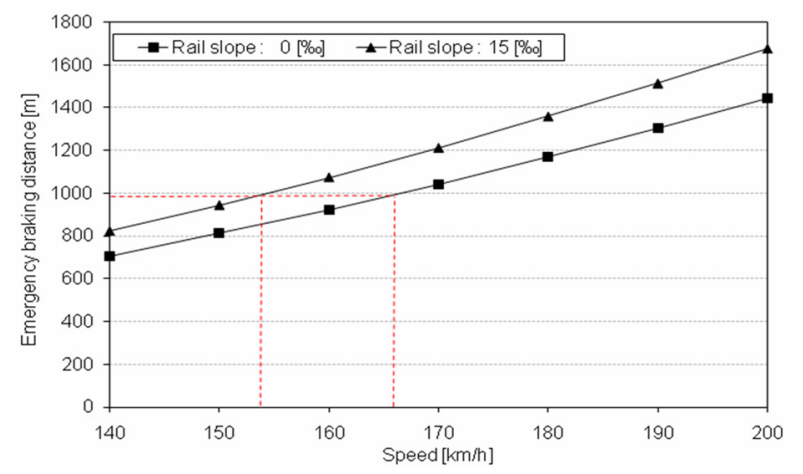

Fig. 6. Necessary emergency braking distance properties of the traction system according to traveling speed
Table 2. Design criteria of the high-speed propulsion system for use in the deep-underground GTX

\begin{tabular}{c|c}
\hline Contents & Specifications \\
\hline Maximum operation speed & $150 \mathrm{~km} / \mathrm{h}$ \\
\hline Maximum design speed & $165 \mathrm{~km} / \mathrm{h}$ \\
\hline Tunnel pattern & $\begin{array}{c}\text { Double line or single parallel } \\
\text { (By-pass Tunnel }: 500 \mathrm{~m})\end{array}$ \\
\hline Acceleration & $2.5 \mathrm{~km} / \mathrm{h} / \mathrm{sec}$ \\
\hline Reaching distance to the max. speed & Below $4.5 \mathrm{~km}$ \\
\hline Emergency braking distance & $1,000 \mathrm{~m}$ \\
\hline Maximum slope of rail & Below $15 \%$ \\
\hline
\end{tabular}

\section{Traction Performance of the LIM Propulsion System}

\subsection{Analysis of the traction force requirements of the LIM propulsion system}

LIM propulsion system has many advantages over conventional propulsion systems, making it a more suitable choice for the deep-underground GTX. The LIM has excellent acceleration and deceleration as well as the ability to climb steep gradients. It has lower construction cost than conventional systems due to its small tunnel cross-section. It is quiet and runs smoothly (no mechanical couplings). Finally, it is cheaper to maintain $[7,8]$. Fig. 7 shows a practical consideration of the LIM propulsion system as applied to the deep-underground GTX. The LIM primary and its control equipment are installed under the deep-underground GTX bogie, and the LIM secondary reaction plate is installed on the rail.

In this study, we analyzed the requirements of the LIM traction force for a LIM propulsion system on vehicles traveling through a double-line tunnel without a by-pass tunnel, as well as a single-line tunnel with a by-pass tunnel, every $500 \mathrm{~m}$. Eq. (4) was used to calculate the necessary traction force at the starting point of the LIM propulsion vehicle, and Eq. (5) was used to calculate the total output power of the LIMs at the terminal speed of the constantthrust-force region. In addition, Eq. (6) was used to calculate the traction force at the terminal speed (120 $\mathrm{km} / \mathrm{h}$ ) of the constant-output-power region on the middlespeed band, and Eq. (7) was used to calculate the traction force at $165 \mathrm{~km} / \mathrm{h}$ [9-11]. These are given as follows:

$$
\begin{gathered}
T_{S}=28.35 \times W \times 1.05 \times \alpha+R_{S} \times W \quad[\mathrm{kgf}] \\
P_{M}=T_{S} \times V_{\text {rated }} / 367.3 \quad[\mathrm{~kW}] \\
T_{120}=P_{M} \div 367.3 / 120 \times \eta \quad[\mathrm{kg}] \\
T_{165}=T_{120} \times 120^{2} / 165^{2} \quad[\mathrm{~kg} f]
\end{gathered}
$$

where $T_{S}$ is the starting traction force of vehicles, $W$ is the total weight of fully loaded vehicles (256 tons), $\alpha$ is the acceleration $(2.5 \mathrm{~km} / \mathrm{h} / \mathrm{s}), R_{S}$ is the starting resistance of vehicles $(5 \mathrm{kgf} / \mathrm{tons}), V_{\text {rated }}$ is the rated velocity of vehicles 
$(60 \mathrm{~km} / \mathrm{h})$, and $P_{M}$ is the output power of the traction motor $(\mathrm{kW})$. The train consists of eight cars, and each car has two LIMs for propulsion. Therefore, a GTX train has a total of 16 LIMs. In addition, the maximum slope of the rail is $60 \%$. Fig. 8 shows the necessary traction force for the LIM propulsion system to propel the deep-underground GTX traction system. As can be seen, the necessary traction force at the starting point of a LIM propulsion vehicle is about $200 \mathrm{kN}$, and the maximum output power of the LIMs at the terminal speed of the constant-thrust-force region is about $3,328 \mathrm{~kW}$. In addition, the traction force at the terminal speed of the constant output power is about 100 $\mathrm{kN}$, and the traction force at $165 \mathrm{~km} / \mathrm{h}$ is about $53 \mathrm{kN}$.

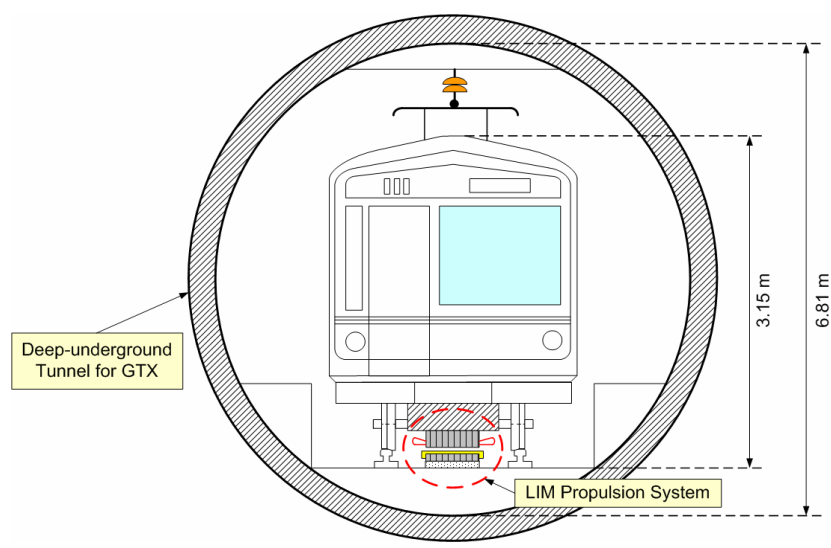

Fig. 7. Practical consideration of the deep-underground GTX and the LIM propulsion system

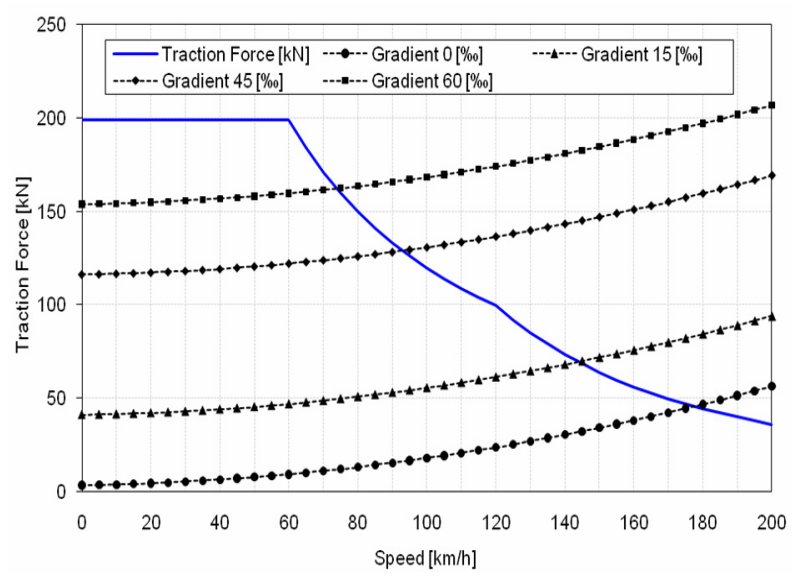

Fig. 8. Necessary traction force for the LIM to propel the deep-underground GTX traction system

\subsection{Analysis of the design and characteristics of the LIM propulsion system}

In this study, an analytical method was used to design a LIM for use in the deep-underground GTX propulsion system. The resulting design is a single-sided, short primary type LIM. Table 3 shows the design specifications of the LIM for use in the deep-underground GTX propulsion system. As shown in Fig. 9, the mixed 2D-3D
Table 3. Design specifications of a LIM for use in a deepunderground GTX propulsion system

\begin{tabular}{c|c}
\hline Contents & Specification \\
\hline Rated output power of the total LIMs & $170 \mathrm{~kW}$ \\
\hline DC-link voltage / Phase voltage & $1,500 \mathrm{~V} / 675.5 \mathrm{~V}$ \\
\hline Rated frequency / Rated speed & $41 \mathrm{~Hz} / 60 \mathrm{~km} / \mathrm{h}$ \\
\hline Phase / Poles & $3 / 10$ \\
\hline Air-gap / Al-sheet thickness & $9 \mathrm{~mm} / 5 \mathrm{~mm}$ \\
\hline Pole pitch / Slot pitch & $252 \mathrm{~mm} / 21 \mathrm{~mm}$ \\
\hline Primary core length / Stack width & $2696 \mathrm{~mm} / 230 \mathrm{~mm}$ \\
\hline
\end{tabular}

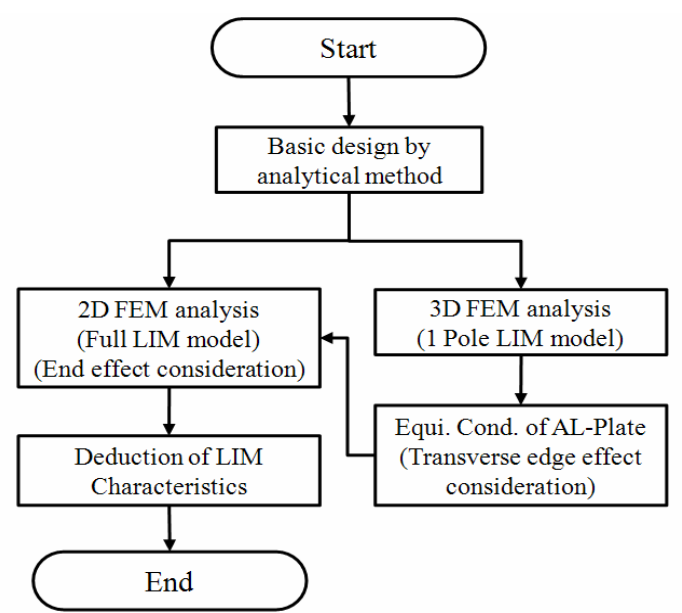

Fig. 9. Analysis flow of the mixed 2D-3D simulation method for a characteristic calculation of the LIM

FEM analysis method was used to analyze the characteristics of the LIM. Here, 3D FEM analysis is necessary for considering the transverse edge effect of the LIM [12-14]. In this study, 3D FEM analysis (using a onepole model as a 3D LIM model) was used to calculate an equivalent conductivity on the $\mathrm{AL}$ sheet by varying the overhang ratio on the secondary AL reaction plate. The transverse edge effect correction factors were calculated using the equivalent amount of eddy current by $3 \mathrm{D}$ analysis of the LIM model. Fig. 10 shows the 3D one pole LIM model and the distribution of the eddy current to calculate the equivalent amount of eddy current on the AL reaction plate. This equivalent conductivity value was applied to the secondary AL sheet of the 2D FEM model, and the property variation of the tangential and normal forces was analyzed at various speed levels $(0-165 \mathrm{~km} / \mathrm{h})$, which is considered the constant slip (0.2). Table 4 shows the correction factors considering the transverse edge effect by varying the overhang ratio and shape of the secondary AL reaction plate. The AL reaction plate model with 1.2 overhang and semi-cap was selected for this study after considering performance and cost. Fig. 11 shows the distribution of the magnetic flux density and the B vectors on the LIM for use in the deep-underground GTX propulsion system under the rated load, via 2D FEM analysis. Fig. 12 shows the comparison of the thrust force requirement and the calculated thrust force for a change in 

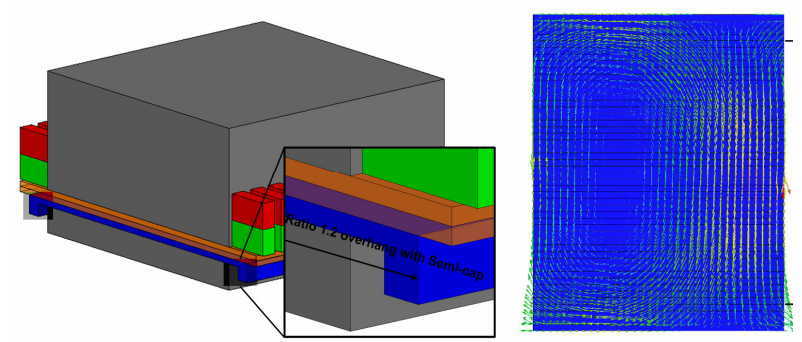

Fig. 10. 3D one pole LIM model and distribution of the eddy current to calculate the equivalent amount of eddy current on the AL reaction plate

Table 4. Correction factors considering the transverse edge effect by varying the overhang ratio and shape of the secondary AL reaction plate

\begin{tabular}{c|c|c|c}
\hline \multirow{2}{*}{ Contents } & $\begin{array}{c}\text { Correction } \\
\text { factor }\end{array}$ & $\begin{array}{c}\text { Equivalent } \\
\text { conductivity } \\
{[\mathrm{mhos} / \mathrm{m}]}\end{array}$ \\
\hline \multirow{2}{*}{\begin{tabular}{c} 
Without overhang \\
\multirow{3}{*}{$\begin{array}{c}\text { With } \\
\text { overhang }\end{array}$}
\end{tabular}} & Overhang 1.1 & 0.7086 & $2.71 \mathrm{E}+07$ \\
\cline { 2 - 4 } & Overhang 1.2 & 0.7777 & $2.97 \mathrm{E}+07$ \\
\cline { 2 - 4 } & Overhang 1.3 & 0.8604 & $3.29 \mathrm{E}+07$ \\
\hline \multirow{4}{*}{\begin{tabular}{c} 
With \\
overhang \\
\cline { 2 - 4 }
\end{tabular}} & Overhang 1.1+Semi_cap & 0.8575 & $3.28 \mathrm{E}+07$ \\
\cline { 2 - 4 } & Overhang 1.1+ Full_cap & 0.8954 & $3.42 \mathrm{E}+07$ \\
\cline { 2 - 4 } & Overhang 1.2+ Semi_cap & 0.8776 & $3.35 \mathrm{E}+07$ \\
\cline { 2 - 4 } & Overhang 1.2+ Full_cap & 0.9059 & $3.46 \mathrm{E}+07$ \\
\cline { 2 - 4 } & Overhang 1.3+ Semi_cap & 0.9363 & $3.58 \mathrm{E}+07$ \\
\cline { 2 - 4 } & Overhang 1.3+ Full_cap & 0.9612 & $3.67 \mathrm{E}+07$ \\
\hline
\end{tabular}
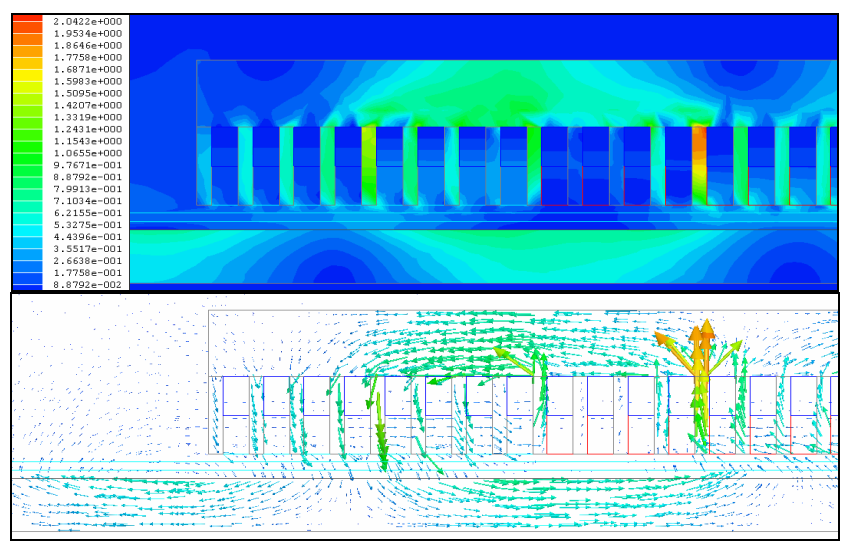

Fig. 11. Distribution of magnetic flux density (B) and B vectors on the LIM under the rated load, via $2 \mathrm{D}$ FEM analysis

the operating speed of the total LIMs. As can be seen, the calculated thrust force at the starting point was about 235 $\mathrm{kN}$. In addition, the traction force at the terminal speed of the constant output power was about $120 \mathrm{kN}$, and the traction force at $165 \mathrm{~km} / \mathrm{h}$ was about $87 \mathrm{kN}$. Fig. 13 shows the thrust force and the normal force properties for a change in the applied voltage and operating speed of the LIM 1 module. As can be seen, a negative value of the

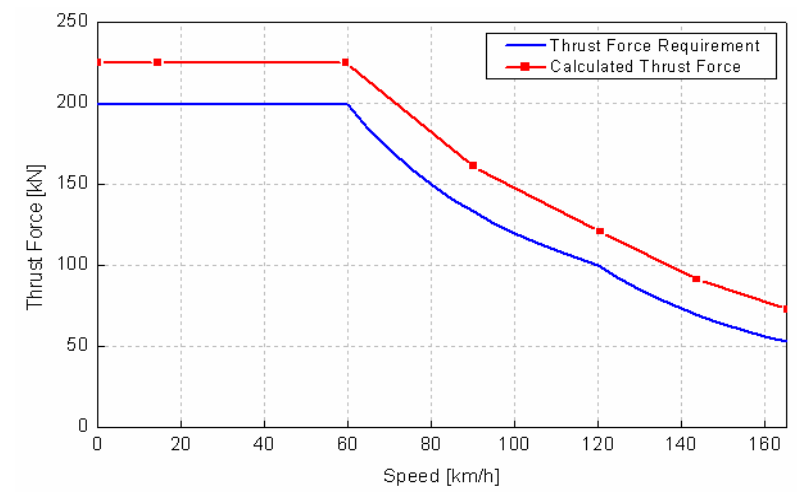

Fig. 12. Comparison of the thrust force requirement and the calculated thrust force for a change in the operating speed of the total LIMs

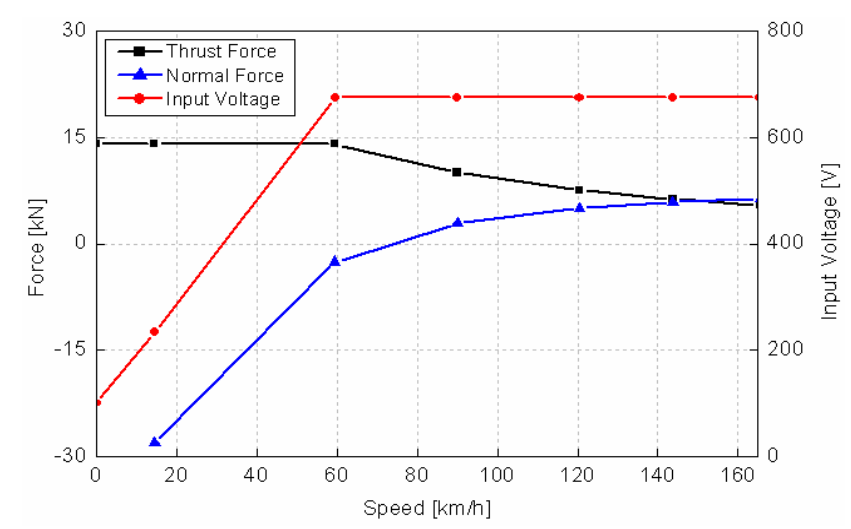

Fig. 13. Thrust force and normal force properties for a change in the applied voltage and operating speed of the LIM 1 module

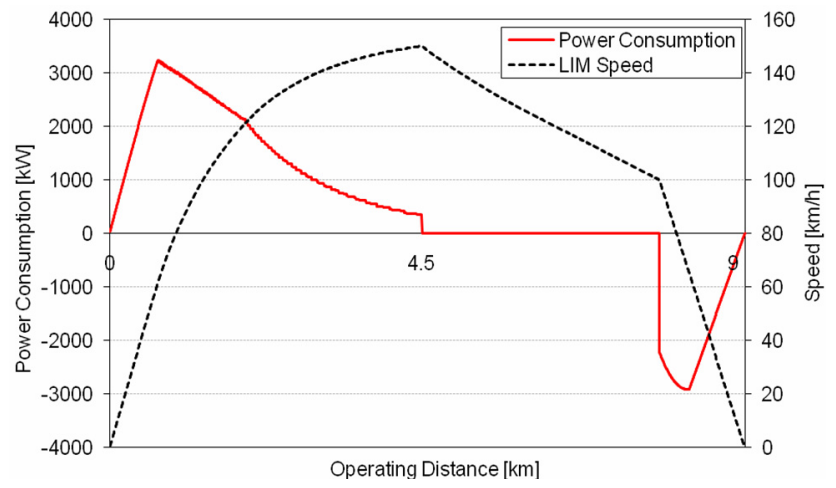

Fig. 14. Total Power consumption of all LIMs installed on the deep-underground GTX vehicles in an arbitrary route

normal force indicates an attraction force. Finally, using the train performance simulation program, the power consumption of a GTX train equipped with a LIM propulsion system was analyzed as it ran an arbitrary route with stations spaced at $9 \mathrm{~km}$ intervals [15-17]. Fig. 14 shows the total power consumption of all the LIMs 
installed on the deep-underground GTX running on an arbitrary route. As shown in Fig. 14, the GTX train reached a speed of $150 \mathrm{~km} / \mathrm{h}$ within $4.5 \mathrm{~km}$, and its maximum power consumption was $3,234 \mathrm{~kW}$. It has been confirmed that the thrust force value calculated via FEM analysis satisfies the traction force requirement for the LIM propulsion system installed on the GTX train traveling through deep-underground tunnels.

\section{Conclusion}

The purpose of this study was to design a LIM suitable for use in the propulsion system of a high-speed underground railway vehicle. In order to accomplish this goal, we analyzed the running resistance properties of a high-speed traction system based on a variety of tunnel types and vehicle organization methods. We then analyzed the power requirement for the traction electric motor to maintain a balanced speed in the high-speed traction system. The element techniques, for the development of a high-speed traction system for the deep-underground GTX, including the design criteria, were presented. Finally, a LIM for use in the propulsion system was designed, and its various performances in a variety of deep-underground tunnels were analyzed using a mathematical method. In conclusion, we confirm that the thrust force value calculated via FEM analysis satisfies the traction force requirement for a LIM propulsion system for use on trains that travel through deep-underground tunnels.

\section{References}

[1] C.B. Park, B.S. Lee, and J. Lee, "A study on the applicability of the conventional TTX propulsion system on the high-speed propulsion system for a deep-underground GTX." International Journal of Railway, Vol. 3, No. 2, pp.54-59, June 2010.

[2] G. Wettschureck, Markus Heim, and Markus Tecklenburg, "Long-term properties of Sylomer ${ }^{\circledR}$ ballast mats installed in the rapid transit railway tunnel near the Philharmonic Hall of Munich, Germany," Rail engineering international, vol.31, no.4, pp. 6-11, 2002.

[3] A. Baron, M. Mossi, and S. Sibilla, "The alleviation of the aerodynamic drag and wave effects of highspeed trains in very long tunnels," Journal of wind engineering and industrial aerodynamics, vol.89, no.5, pp. 365-401, 2001.

[4] P. Lukaszewicz, "Running resistance and energy consumption of ore trains in Sweden," Journal of rail and rapid transit, Proceedings of the Institution of
Mechanical Engineers. Part F, vol.223, no.2, pp. 189198, 2009.

[5] T. Obata, S. Sugawara, "Maintenance and Management of the Undersea Section of the Seikan Tunnel," Japanese railway engineering, vol.39, no.1, pp. 16-20, 1999.

[6] Lee H.-W., Lee S., Park C., Lee J., Park H.-J., "Characteristic Analysis of a Linear Induction Motor for a Lightweight Train according to Various Secondary Schemes", International Journal of Railway, vol.1, no.1, pp. 6-11, 2008.

[7] Wei $\mathrm{Xu}$, et al., "Equivalent circuits for single-sided linear induction motors" IEEE Trans. Industry Applications, vol. 46, no. 6, pp. 2410-2423, 2010.

[8] A.Z. Bazghaleh, M.R. Naghashan, and M.R. Meshkatoddini, "Optimum design of single-sided linear induction motors for improved motor performance” IEEE Trans. Magnetics, vol. 46, no. 11, pp. 3939-3947, 2010.

[9] I. Boldea, and S.A. Nasar, "Linear motion electromagnetic devices", New York: Taylor \& Francis, 2001, pp. 64-69.

[10] Jacek F. Gieras, "Linear induction drives", Tokyo: Oxford: Clarendon, 1994, pp.12-16.

[11] T.A. Lipo, "Introduction to AC Machine Design, Vol.1", Madison Wisconsin: University of Wisconsin, 1996, pp.333-338.

[12] Sakae Yamamura, "Theory of Linear Induction Motors", Tokyo: University of Tokyo Press, 1978, pp.111-118.

[13] R.C. Creppe, J.A. Covolan Ulson, and J.F. Rodrigues, "Influence of design parameters on linear induction motor end effect” IEEE Trans. Energy Conversion, vol. 23, no. 2, pp. 358-362, 2008.

[14] Y. Nozaki, T. Koseki and E. Masada, "Analysis of Linear Induction Motors for HSST and Linear Metro using Finite Difference Method," Proc. LDIA2005, pp 168-171, 2005.

[15] A.H. Isfahani, B.M. Ebrahimi, and H. Lesani, "Design optimization of a low-speed single-sided linear induction motor for improved efficiency and power factor” IEEE Trans. Magnetics, vol. 44, no. 2, pp. 266-272, 2008.

[16] Y. Srinivasa Rao, and M.C. Chandorkar, "Rea-time electrical load emulator using optimal feedback control technique" IEEE Trans. Industrial Electronics, vol. 57, no. 4, pp. 1217-1225, 2010.

[17] A. Das, K. Sivakumar, R. Ramchand, C. Patel, and K. Gopakumar, "A pulsewidth modulated control of induction motor drive using multilevel 12-sided polygonal voltage space vectors" IEEE Trans. Industrial Electronics, vol. 56, no.72, pp. 2441-2449, 2009. 


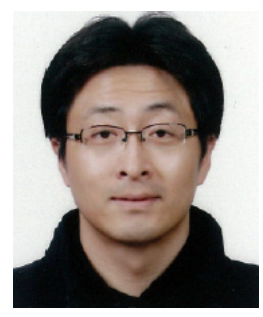

Chan-Bae Park He received his M.S. degree in Electrical Engineering from Seoul National University, Seoul, Korea, in 2003. Since 2009, he has been completing the Ph.D. course in electrical engineering from Hanyang University, Seoul, Korea. His research interests include design and analysis of motor/generator, transformer, and superconducting devices for energy conversion systems. Currently, he is working to develop linear propulsion systems for railway transit.

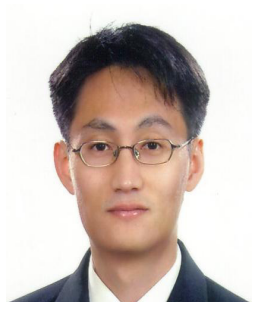

Hyung-Woo Lee He received his M.S. degree from Hanyang University, Seoul, Korea, in 2000, and his Ph.D. from Texas A\&M University, College Station, TX, in 2003, both in Electrical Engineering. Since 2006, he has been a Senior Researcher at the Korea Railroad Research Institute, Uiwang, Korea. His research interests include design, analysis and control of motor/generator, power conversion systems, applications of motor drives (such as in Maglev trains and robots), and modern renewable energy systems.

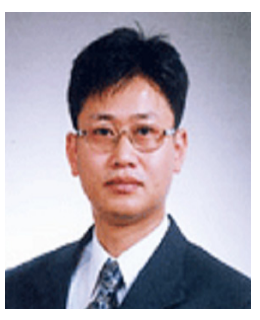

Ju Lee He received his M.S. degree from Hanyang University, Seoul, South Korea, in 1988, and his Ph.D. from Kyusyu University, Japan in 1997, both in Electrical Engineering. He joined Hanyang University in September, 1997 and is currently a Professor of the Division of Electrical and Biomedical Engineering. His main research interests include electric machinery and its drives, electromagnetic field analysis, new transformation systems such as hybrid electric vehicles (HEV), and high-speed electric trains and standardization. He is a member of the IEEE Industry Applications Society, Magnetics Society, and Power Electronics Society. 